\title{
Zur Kirchenpolitik des Bischofs Kallist.
}

\section{Vom Herausgeber.}

Die Frage nach der Stellung des römischen Bischofs Kallist in der Bußdisziplin ist neuerdings Gegenstand sehr lebhaft geführter Debatten geworden, an denen sich namentlich katholische Gelehrte beteiligt haben. ${ }^{1}$ Das Hauptinteresse haftet bei diesen Erörterungen an der Frage, ob die Praxis des Kallist eine Neuerung auf dem Gebiete der kirchlichen Disziplin darstellt, oder ob er nur eine bereits in Übung befindliche Sitte durch eine ausdrückliche Verordnung sichergestellt habe. Ist letzteres der Fall, so erscheint der Bischof Kallist als .Vertreter der kirchlichen Tradition, die er gegen die unberechtigten Angriffe rigoristischer Parteien und Sekten mit Erfolg zu verteidigen bemüht war. Es ist nicht $\mathrm{zu}$ verkennen, daß an dieser Fragestellung der katholische Theologe einen lebhafteren Anteil nehmen wird, als der nichtkatholische, und ebenso, daß bei der Entscheidung der Frage sich bei jenen leicht Erwägungen einstellen, die unbewußt die rein historische Untersuchung $z u$ stören vermögen. Immerhin ist die Sache für die Kenntnis der inneren Politik des römischen Bistums in dem ersten Drittel des 3. Jahrhunderts von solcher Bedeutung, daß eine erneute Prüfung der jetzt in den Vordergrund gestellten Gesichtspunkte zur Pflicht wird.

\section{I.}

Die Hauptquelle für die Geschichte der Bußdisziplin sind die beiden Schriften Tertullians, zu denen die Nachrichten Hippolyts über den Episkopat des Kallist [Philosophumena IX, 12] hinzukommen. Es ist zu

1 Die Erörterungen wurden hervorgerufen durch ein Programm von Gerhard Esser, die Bußschriften Tertullians de paenitentia und de pudicitia und das Indulgenzedikt des Papstes Kallistus, Bonn 1905. Die Frage ist im Anschluß daran in zahlreichen Aufsätzen behandelt worden. Ich habe sie in der 2 . Auflage meiner Ausgabe von Tertullian, de paen. und de pud., Tübingen 1910, S. VIII verzeichnet. Diese Ausgabe lege ich im Folgenden zugrunde, auch für die §-Ziffern. Das Beste über die Frage findet sich bei K. Müller, Kirchengesch. I, 1892, S. 114 f. 
beklagen, daß wir keine Quellen besitzen, die auf eine Kallist nahestehende Seite zurückgehen. Denn wenn auch der Satz richtig ist, daß Hippolyts Bericht ,in den Tatsachen glaubwürdig, in ihrer Begründung einseitig " ist, ${ }^{1}$ so kommt eben doch auf die Gruppierung der Tatsachen viel an und auch darauf, daß sie nicht einseitig ausgewählt oder aus ihren Zusammenhängen herausgelöst werden. Zur Vervollständigung dessen, was sich aus Tertullian entnehmen läßt, sowie zur richtigen Beurteilung der gesamten Lage ist Hippolyts Bericht nicht $\mathrm{zu}$ entbehren.

Daß Tertullians Bußschriften in einem inneren Zusammenhang stehen, läßt sich nicht in Abrede stellen. Wenn er nach einer temperamentvollen Klage über die Schändlichkeit des römischen Bischofs, der die Ohren der Kirche, der reinen Jungfrau, durch die Botschaft von der Vergebung der Unzuchtsünden beleidigt habe, fortfährt: „Das wird also einen weiteren Anklagepunkt gegen die Psychiker bilden, zugleich gegen meine frühere Gesinnungsgemeinschaft mit ihnen, durch den sie mir in noch höherem Maße den Vorwurf der Leichtfertigkeit machen können" [de pud. 1,10] - so nimmt er damit offenbar auf die in de paenitentia entwickelten Ansichten Bezug. Auf die Gefahr hin, von seinen Gegnern eines leichtfertigen Gesinnungswechsels beschuldigt zu werden, desavouiert er selbst seine frühere Meinung. Esser hat mit Recht darauf hingewiesen, daß eine andere Interpretation dieser Stelle unmöglich sei. ${ }^{2}$ Dann ergibt sich daraus mit Evidenz, daß Tertullian in seiner kirchlichen Periode die Meinung vertrat, alle, auch die gröbsten Sünden, könnten durch eine zweite Buße gesühnt werden.

Dem entspricht auch vollkommen der Inhalt von de paenitentia. ${ }^{3}$

1 A. Werminghoff in Schieles Handwörterbuch I, 1537.

2 Bonner Programm 1905, S. 8 f.

3 Die Datierung von de paen. mag hier auf sich beruhen. Nach Kellner [Katholik 1879, 2, $561 \mathrm{ff}$.] und Noeldechen [Texte und Unters. V, 2, 1888, 59 ff.], denen sich auch Adam anschlieBt [Katholik 1908, 2, 348 f.], ist die Schrift Ende 203 oder Anfang 204 abgefapt. Harnack [Chronol. d. altchr. Lit. II, 2, 2722] will die für dies Jahr vorgebrachten Gründe nicht gelten lassen, und man wird ihm darin recht geben müssen, $\mathrm{daB}$ sie nicht durchschlagend sind. Einleuchtend ist nur der Hinweis auf Tertullians Bemerkung über die Tätigkeit vion Vulkanen, durch die Städte teils vernichtet worden seien, teils in ihrer Existenz so bedroht würden, daß sie das Schicksal der verschütteten Orte von Tag zu Tag erwarten müBten [de paen. 12, 2]. Aus Cassius Dio LXXVI, 2 ergibt sich, daß 203 ein Ausbruch des Vesuv die Gemüter nicht weniger in Aufregung versetzte, als die abscheulichen Grausamkeiten des kaiserlichen Günstlings Rlautian, des Schwiegervaters Caracallas. Allein über eine gewisse Wahrscheinlichkeit kommt man auch hier nicht hinaus. Denn seit dem großen Ausbruch des Jahres 79 ist der Vesuv nie ganz zur Ruhe gekommen. 
In ihr rechtfertigt Tertullian [c. $7 \mathrm{ff}$.] nicht ohne ciniges Widerstreben die zweite Buße, durch die nach der Taufe begangene Sünden gesühnt werden können. Die Notwendigkeit dieser Buße sieht er darin begründet, daß der Christ, der durch die Taufe dem Herrschaftsgebiete des Teufels entrückt sei, eben darum von diesem um so eifriger verfolgt werde: der Teufel "wütet dann ganz besonders heftig, wenn er merkt, daß der Mensch von ihm vollkommen befreit worden ist; er wird um so hitziger, je mehr er gedämpft wird“ $[7,7]$. Damit diese teuflischen Absichten zuschanden würden, hat Gott die zweite Buße eingesetzt. Um etwa auftauchenden $Z$ weifeln an der Wirksamkeit dieser paenitentia secunda $z \mathrm{u}$ begegnen, verweist Tertullian [c. 8] auf eine Anzahl von Schriftstellen, durch die diese milde Praxis gesichert erscheine. Es sind dies die Briefe am Anfang der Apokalypse an die Epheser, Thyatirener, Sarder, Pergamener, Laodicener. Die getadelten Sünden sind: deserta dilectio, stuprum, idolothytorum esus, non plena opera, perversa doctrina, fiducia divitiarum. Wenn der Apokalyptiker, so folgert Tertullian, die Gemeinden wegen dieser Sünden zur Buße ermahnt, so muß er der Meinung gewesen sein, daß der Buße auch die Vergebung folge. Daraus folgt, da sich Tertullian ausdrücklich auf den heiligen Geist beruft, der in diesen Briefen zu den Gemeinden rede, daß auch er die hier genannten Sünden für vergebbar betrachtete. Und da ausdrücklich die Unzuchtsünden und die Idololatrie genannt sind, so kann auch hinsichtlich dieser Sünden Tertullian von einer Ausnahmestellung nichts gewußt haben.

Als weiteres Argument führt Tertullian die an einzelnen Schriftstellen [Jer 8, 4. Hos 6,6] ausgesprochene Überzeugung von Gottes Güte und Milde an, für die auch die Gleichnisse Lk 15 einen hinreichenden Beweis liefern. Der verlorene Groschen ist das Bild des restitutus peccator, ebenso das verirrte Schaf, der verlorene Sohn. Gott nimmt den Sünder, selbst wenn er das empfangene Erbe verschleudert hat, auf, nur weil er wieder zurückkehrt. Über diese Umkehr des Sünders freut er sich mehr, als über die Gerechtigkeit der Frommen. Die Logik dieser Beweisführung zwingt zu der Annahme, daß für Tertullian, als er de paenitentia schrieb, noch kein Unterschied zwischen delicta remissibilia und irremissibilia bestand, daß er vielmehr alle ohne Ausnahme, auch Unzucht und Götzendienst, durch die zweite Buße gesühnt werden ließ.

Tertullian hat sich in de paenitentia mit der kurzen Skizzierung des Beweises begnügt. Aber sein Gedankengang ist vollständig klar. Er sucht nach direkten Beweisstellen aus der Schrift, an denen die 
Vergebbarkeit aller Sünden ausgesprochen ist, und findet sie in den Briefen der Apokalypse. Er stellt ferner dogmatische Erwägungen an, und sieht in der durch die Schrift bezeugten Güte Gottes eine weitere Stütze seiner Meinung. Wenn er seine Beweisführung mit den Worten einleitet: id (nämlich habere cui satisfacias) si dubitas, evolve quae spiritus ecclesiis dicat, so kann sich das auf einen fingierten Gegner beziehen; es kann aber auch gegen die Rigoristen gerichtet sein, von denen eine zweite Buße überhaupt verworfen wurde. Da Tertullian in seiner Schrift jedoch von solchen Gegnern sonst nicht redet, wird man in diesen Einführungsworten nur eine seiner rhetorischen Formeln zu sehen haben, durch die er den Übergang zu einem neuen Teil seiner Erörterung gewinnt.

Spricht nun Tertullian im Namen der gesamten Kirche? Man pflegt die Sache gewöhnlich so anzusehen. Aber gerade bei der Geschichte der christlichen Sitte rächt sich kein Fehler schwerer, als der der Generalisierung. Man mag zugeben, daß Tertullian in diesem Traktat nicht nur seine eigne, persönliche Meinung ausspricht, sondern daß er darin die kirçhlichen Anschauungen den Katechumenen und den $\mathrm{Ge}-$ fallenen gegenüber vertritt. Auch so beweist die Schrift nur etwas für die kirchliche Sitte in Karthago. Sie ohne weiteres als ein Zeugnis auch für die Sitte der übrigen Kirchen zu verwerten, hätte nur dann einen Sinn und ein Recht, wenn die christliche Kirche damals in Lehre und Brauch eine Einheit gewesen wäre, was sie eben tatsächlich nicht war. Daß Tertullian nichts von einer Verschiedenheit der Anschauungen sagt, beweist dagegen nichts. Verfolgte er mit seiner Schrift rein praktische Ziele, so lag für ihn gar kein Anlaß vor, Abweichungen von den in ihr vorgetragenen Ansichten zu erwähnen, selbst wenn ihm solche bekannt waren. Aus diesem Grunde erscheint die stillschwreigend gezogene Folgerung, .daß das, was Tertullian hier vortrage, kirchliche Lehre sei, darum auch für Rom zu gelten habe, als hinfällig. Über die Bußpraxis Roms am Anfang des 3. Jahrhunderts lehrt uns de paenitentia nichts. ${ }^{1}$

Den unmittelbaren Anstoß zur Abfassung der in der montanistischen Zeit entstandenen Schrift de pudicitia ${ }^{2}$ empfing Tertullian durch

1 Wenn K. Müller, Kirchengesch.J, 1892, S. 115 die karthagische Sitte als „jedenfalls" auch für Rom geltend reklamiert, so dürfte das zu weit gehen. Ohne bestimmtes Zeugnis läbt. sich das nicht behaupten.

2 Die Abfassungszeit von de pud. ergibt sich aus dem, was sich über die Person des in ihr bekämpften römischen Bischofs ausmachen läßt. $\mathrm{DaB}$ sie an das Ende von Tertullians schriftstellerischer Tätigkeit zu setzen sei, nicht an den Anfang seines

Zeitschr. f. d. neutest. Wiss. XI. Jahrg. 1910.

10 
ein Ereignis, das er c. 1,6 folgendermaßen beschreibt: audio edictum esse propositum, et quidem peremptorium. Pontifex scilicet Maximus, guod cst episcopus cpiscoponum, edicit: ego moechiae et fornicationis delicta pacnitentia functis dimitto. Daß hier eine Anspielung auf den römischen Bischof vorliege, macht der ironische Titel Pontifex maximus unzweifelhaft, der bei dem Bischof von Karthago ${ }^{1}$ oder einer andern Metropole keinen Sinn hätte. Es fragt sich nur, welcher römische Bischof gemeint ist. Die früher wohl allgemein vertretene Ansicht, es sei der Bischof Zephyrin gemeint, ${ }^{2}$ ist neuerdings meist zugunsten des Kallist aufgegeben worden. Allerdings hat kürzlich Hauck ${ }^{3}$ wieder Zephyrin empfohlen. Er findet die Annahme, daß Kallist gemeint sei, ansprechend, aber undurchführbar, weil nach de pud. $5 \mathrm{f}$. es sicher sei, daß in dem von Tertullian bekämpften Edikt die Unzuchtsünden allein als vergebbar bezeichnet gewesen wären, während nach Hippolyt es ebenso sicher sei, daß Kallist die Vergebbarkeit aller Sünden behauptet habe. Der Grund wäre nur dann wirklich beweiskräftig, wenn die Annahme einer Entwicklung der kirchlichen Gesetzgebung unter Kallist ausgeschlossen erschiene. Das läßt sich jedoch nicht beweisen. Daß Zephyrin nicht gemeint ist, sondern Kallist, 'scheint aus der Bezeichnung benedictus papa $[13,7]$ hervorzugehen, die mit Wahrscheinlichkeit auf einen Märtyrerbischof zurückzuführen ist. Denn in ad martyras redet 'Tertullian die Märtyrer konstant mit benedicti an [c. 1.2.3.5], die Märtyrerinnen mit benedictae [c. 4]. Wenn er de baptismo 20 auch die Neugetauften in derselben Weise apostrophiert, so erklärt sich das aus dem Zusammenhang; sie sind "Gesegnete“, weil sie Gottes Gnade in der Taufe empfangen haben, ebenso wie ihre Leiber corpora benedicta genannt werden [c. 8], weil bei der Taufe die Benediktionsgebete darüber gesprochen worden sind. $\mathrm{Daß}$ in de cultu fem. II, 5.9 benedictae als Anrede gebraucht wird, mag dem Predigtstil entsprechen,

Uberganges in das montanistische Lager, darf man heute als ausgemacht ansehen; vgl. Harnack, Chronol. d. altchr. Lit. II, 2, 286. Eine genauere Datierung ist leider nicht mehr möglich.

1 F. Münter, Primordia eccl. Afric., p. 45 sq. vertrat diese Ansicht wohl nur auf die Autorität Orsis [dissert. de capitalium criminum absolutione, p. 98 sqq.] u. a., weil er meinte, daß de pudicitia gegen die Kirche von Karthago gerichtet sei, in dieser aber der römische Bischof keine Jurisdiktionsgewalt gehabt habe. Die Voraussetzung ist aber nicht $\mathrm{zu}$ beweisen, daher auch die Folgerung hinfallig.

2 Sie war so eingewurzelt, daß Binterim [Die vorzügl. Denkwürdigkeiten d. christkath. Kirche III, 90] die Stelle aus Tertullian so zitierte: Zephyrinus, Pontifex Maximus, Episcopus Episcoporum, dicit.

${ }^{3}$ Real-Enzykl. ${ }^{3}$ III, 641. 
läßt sich aber nicht mit dem benedictus papa, das neben bonus pastor einen besonderen Akzent hat, nicht vergleichen. ${ }^{1}$ Ist nun dadurch wahrscheinlich, daß ein Märtyrerbischof angeredet-wird, so muß Zephyrin ausgeschieden werden. Von ihm ist nichts bekannt, was dazu veranlassen könnte, ihn durch das Prädikat benedictus auszuzeichnen. Anders Kallist. Die boshafte Schilderung Hippolyts ${ }^{2}$ von dem mißglückten Bankunternehmen, dem Bankerott und der vereitelten Flucht des Sklaven Kallist ist bekannt. Zur Tretmühle verurteilt, wußte Kallist es durchzusetzen, daß ihn Karpophorus, sein Herr, freigab. Da sich aber die seine Befreiung bewirkenden Angaben als falsch herausstellten, hatte er abermals Strafe, wohl wiederum Einsperrung in der Tretmühle, zu befürchten. Kallist habe nun, behauptet Hippolyt, freiwillig aus dem Leben scheiden wollen und um gleichsam einen "schönen " Tod zu haben, sei er unter dem Vorwand, die Gläubiger aufsuchen zu wollen, am Sabbat in die versammelte Synagogengemeinde eingedrungen und habe dort einen Tumult erregt. ${ }^{3}$ Man wird hier die Motive, mit denen Hippolyt die Erzählung ausschmückt, beiseite lassen dürfen. Sie sind in sich so unwahrscheinlich wie möglich. Wenn Kallist wirklich sterben wollte, fand er wohl andere Mittel als das, daß er sich von einer erbitterten Judenmenge den Schädel einschlagen ließ. Eher wird man annehmen dürfen, daß er mit seinen Gläubigern - daß sie in erster Linie unter den Juden zu suchen waren, kann nicht überraschen - ein Arrangement treffen wollte. Daß sein Erscheinen inmitten der zum Sabbatgottesdienst vor der Synagoge versammelten Menge lebhafte Auseinander-

1 Der Gebrauch von sanctus für die Märtyrer findet sich erst viel später. Die schöne Studie von Delehaye [Anal. Boll. 1909, 145-200] zeigt die Zusammenhänge mit dem römischen Heidentum auch an diesem Punkte. Für Tertullian sind die Märtyrer noch nicht sancti, wie er sich denn über sie recht despektierlich äußerte, wenn sie nicht zu seiner Partei gehörten [de ieiun. 12].

2 Philosoph. IX, 12, p. 452 sqq.

3 Der Text ist an der Stelle [p. 454, 26-30] nicht ganz klar. Zwar der Gebrauch von kàtactacıáŻıv, das im Sinne von "aufrührerisch machen, verstören", genommen ist, den Döllinger [Hippolyt u. Kallist S. 1195] beanstandet, bietet kaum zu

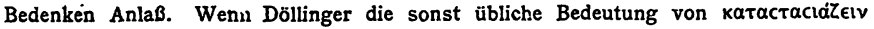
„durch einen Aufruhr oder eine politische Faktion unterdrücken ${ }^{\alpha}$ mit unserer Stelle nicht in Einklang bringen kann, so hat er recht. Nur hätte er sich nicht so fest auf die Lexika verlassen sollen, die für das Wort keine allgemeinere Bedeutung zu belegen wissen. Denn so gut katactacıactikóc ,aufrührerisch" heißen kann ( $\theta$ poûc $\kappa_{.}=$ein unwilliges Gemurmel Heliod. VII, 19), so sicher kann auch das Verbum im

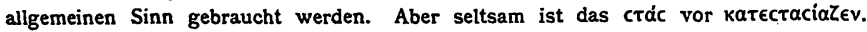
Schneidewin und Duncker vermuten Emctác. Dann wäre der Sinn: vor der Synagoge stehend brachte er sie in Erregung. 
setzungen erwcckte, wird niemand auffallend erscheinen, der die Lebhaftigkeit der Juden in allen geschäftlichen Angelegenheiten kennt. Kallist erhielt eine Tracht Prügel und wurde vor den Stadtpräfekten geschleppt. ${ }^{1}$ Die Beschuldigung, die man hier gegen ihn erhob, lautete: „Die Römer haben uns gestattet, die väterlichen Gesetze öffentlich zu verlesen; dieser Mann ist aber eingedrungen und hat uns daran gehindert, indem er einen Tumult verursachte durch seine Behauptung, er sei ein Christ." Die Verhandlungen endeten damit, daß Kallist trotz des Einspruchs seines Herrn auf die Anklage der Juden hin zur Bergwerksarbeit nach Sardinien verbannt wurde.

Aus der Erzählung des Hippolyt geht deutlich hervor, daß die Verurteilung von seiten des Stadtpräfekten erfolgte, weil Kallist als Christ angegeben wurde, nicht weil er den jüdischen Gottesdienst gestört hatte. Sonst hätte es gar keinen Sinn, daß Karpophorus vor dem Präfekten behauptete, Kallist sei gar kein Christ. ${ }^{2}$ Karpophorus hatte ein Interesse daran, daß Kallist nicht etwa zum Tode verurteilt würde; er mochte auch den Juden den Triumph nicht gönnen. Dennoch vermochte er die Bestrafung nicht zu verhindern. Daher konnte kein Zweifel sein, daß Kallist wirklich als Märtyrer zu betrachten war. Wenn nun der Amnestieerlaß, den Marcia bei Kommodus erwirkte, auch ihm die Freiheit wiedergab, so galt er der Gemeinde wie jeder andere der damals aus den Bergwerken Zurückgekehrten. Auf diese Episode spielt Tertullian unzweideutig an, wenn er mit bitterer Ironie bemerkt: alii ad metalla confugiunt et inde communicatores revertuntur, ubi iam aliud martyrium necessarium est delictis post martyrium novis $[21,2]$. Das trifft wörtlich für Kallist $\mathrm{zu}$, und die ausgesuchte Bosheit dieser Worte konnte keinem Leser verborgen bleiben, sofern ihm die Antecedentien des römischen Bischofs bekannt waren.

Besteht nun demnach über die Person des in de pud. angegriffenen Bischofs kaum ein begründeter Zweifel, so ist andererseits einigermaßen dunkel, was es mit dem von Tertullian genannten Edikt auf sich hat. In den bisherigen Untersuchungen ist man über einige Punkte, die der

1 Nach jüdischem Gesetz mußte der Sabbat von Gerichtsverhandlungen freibleiben (Schürer, Gesch. d. jüd. Volkes ${ }^{3} I I, 210 \mathrm{f}$ ). Wie es jedoch mit der Innebaltung der Sabbatordnung in der Diaspora stand, zeigt Martyr. Polyc. 13, 1.

- 2 Die Behauptung kann Karpophorus unmöglich aus den Fingern gesogen haben. Sie ist berechtigt gewesen, wenn man annimmt, daB Hippolyt von der Gemeinde ausgeschlossen worden war. $\mathrm{Da}$ er sich Depotunterschlagungen hatte zuschulden kommen lassen, durch die Witwen und andere Gemeindeglieder um ihr Geld gekommen waren, konnte wohl der Ausschluß erfolgen; vgl. Plinius, ep. X, 96, 7. 
Klarstellung bedürfen, allzu rasch hinweggegangen oder hat sie überhaupt noch nicht ins Auge gefaßt. Tertullian sagt [1, 6]: audio etiam edictum esse propositum et quidem peremptorium. Den Inhalt dieses

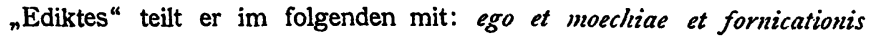
delicta poenitentia finctis dimnitto. Der Wortlaut entspricht offenbar der. Form amtlicher Publikationen. Nach Sueton [Caes. 80] fand man, als Caesar Peregrinen in den Senat aufgenommen hatte, ein ironisch gemeintes Edikt angeschlagen, ${ }^{1}$ des Inhaltes: Bonum factum! Ne quis senatori novo curiam monstrare velit. Von ähnlicher Knappheit ist das gegen Vitellius gerichtete Spottedikt der Ástrologen, ${ }^{2}$ während andere, der Materie entsprechend, wohl umständlicher abgefaßt waren, ${ }^{3}$ aber stets nur den Inhalt der Verordnung bekannt gaben. Damit fällt nun jeder Grund weg, außer diesem Satz noch irgend etwas von dem "Edikt" zu ermitteln, wohl gar es zu einer ausführlichen Kundgebung mit eingehender Begründung zu stempeln. Denn nach den angeführten Beispielen ist das Wesen des Ediktes seine prägnante Kürze. Da die Edikte öffentlich angeschlagen wurden, war auch jede Weitschweifigkeit ausgeschlossen. Den schüchternen Versuch, den ich in meiner Jugendschrift unternommen habe, ${ }^{4}$ das Edikt zu rekonstruieren, kann ich daher heute ebensowenig aufrecht erhalten, wie ich den sehr viel selbstgewisseren, den Rolffs bald danach unternahm, ${ }^{5}$ für irgendwie gelungen ansehen kann.

Man wird sich zunächst darüber klar $z u$ werden haben, welcher Tatbestand denn überhaupt dem Angriff Tertullians zugrunde lag. Denn daß nur ironisch von einem "Edikte“ die Rede ist, daß daher auch die durch dieses Wort bestimmten Phrasen in der nächsten Umgebung nicht für bare Münzen genommen werden dürfen, sollte eigentlich keines Beweises bedürfen. Wenn Tertullian von den durch die Bischöfe bei bestimmten Anlässen angeordneten allgemeinen Fasten den Ausdruck edictum gebraucht, ${ }^{6}$ so ist das nicht ironisch und ent-

1 Der terminus technicus lautet: libellus est propositus.

2 Vgl. Suet., Vitellius 14: exacerbatus, quod post edictum suum, quo iubebat intra K'al. Oct: urbe Italiaque mathematici excederent, statim libellus est propositus et Chaldaeos dicere: Bonum factum! Ne Vitellizs Germanicus intra eundem Kalendarum diem ussguam esset.

3 Vgl. auch K. G. Bruns-Gradenwitz, Fontes iuris Rom. antiqui 5, 1910, I, p. 249 sqq.

+ Tertullians Schriften de paen. ùnd de pud. mit'Rücksicht auf die Bußdisziplin untersucht. Diss. Gießen, 1890.

5 Das Indulgenzedikt des Papstes Kallist (Texte u. Untersuchungen XI, 3), 1893.

6 Bene autem, guod et episcopi universae plebi mandare iciunia adsolent, non dico de indistria stipium conferendarum, ut vestrac capturae est, sed interdum et ex aliqua 
spricht durchaus den 'Tatsachen. Denn eine derartige, der Gemeinde offiziell bekannt gegebene Anordnung, die man sich auch sehr wohl als durch Anschlag an den Kirchentüren publiziert denken kann, war vollkommen analog $\mathrm{zu}$ irgend einem von dem Magistrat erlassenen Edikt. Aber wie soll man sich das angebliche Edikt des Kallist in der Bußfrage denn vorstellen? Es wird niemand im Ernst glauben, da $\beta$ ein Satz wie der von Tertullian angezogene je wirklich durch öffentlichen Anschlag bekannt gemacht worden sei. Wenn er meint, sie gehöre in die Bordelle; dort, sub ipsis libidinum titulis d. h. unter den Plakaten der Dirnen, ${ }^{1}$ sei der Platz für einen solchen Erlaß, so ist der Hohn so offenkundig, da $\beta$ man erkennt, wie Tertullian den Gegner um jeden Preis, auch durch die niedrigsten Mittel ins Unrecht zu setzen bemüht ist.

Aber er fährt dann fort $[1,8]$ : sed hoc in ecclesia legitur et in ecclesia pronuntiatur et virgo est. absit, absit a sponsa Christi tale praeconium! Damit scheint er denn doch eine offizielle Veröffentlichung in der Kirche anzudeuten. Aber dem widerspricht der Inhalt des Satzes. Welchen Sinn könnte eine kirchliche Verkündigung haben, die nur die subjektive Willensmeinung eines Bischofs, kraft deren er bestimmten Sündern Vergebung angedeihen zu lassen erklärt, zum Ausdruck bringt? Wäre in dem Satz gesagt, daß in Zukunft in der römischen und in den unter der Jurisdiktion des römischen Bischofs stehenden Gemeinden diese Sünder nach geleisteter Buße wiederaufgenommen werden könnten, so wäre der Sinn eines Ediktes gewahrt. ${ }^{2} \mathrm{Da}$ das nicht der Fall ist, wird man nicht umhin können anzunehmen, daß Tertullian eine etwas selbstbewußte Äußerung des Kallist, in der er die Normen offenbarte, nach denen er $\mathrm{zu}$ verfahren gedenke, höhnisch als edictumn peremptorium d. h. einen, den Streitfall definitiv erledigenden Erla ${ }^{3}$ be-

sollicitudinis ecclesiasticae causa. itaque si et ex hominis edicto et in unum omnes

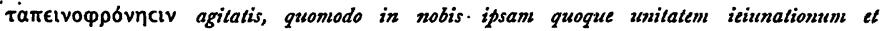
xerophagiarum el stationum denotatis, [de ieiun. 13.]

$1 \mathrm{Zu}$ diesen tituli vgl. Juvenal, sat. VI, 123; Martial., epigr. XI, 45.

2 Vgl. Kipp bei Pauly-Wissowa V, 1941, 44 ff.: „Das Edikt kann sowohl befehlen, als zukünftige Maßregeln des.Magistrates ankündigen. In Jurisdiktionsedikten wiegt das letztere vor, ohne das erste ganz zu verdrängen."

3 Der Begriff des edictum peremplorium ist, wie mir O. Eger freundlichst mitteilt, nur als prozessualer bekannt [s. Kipp in Pauly-Wissowa IV, $1167 \mathrm{~s}$. v. contumacia 2. 3]. Es bedeutet die dritte Ladung, die mit der Drohung verbunden war, da $B$ im Falle des Ausbleibens des Angeklagten bei dem Termin ohne seine Anwesenheit (in contumacia) verhandelt werden würde. Demnach scheint Tertullian auch hier einen juristischen Terminus rhetorisch benutzt $z u$ haben, über dessen eigentliche Bedeutung er sich nicht klar war; vgl. zu dieser Frage S. Schloßmann, Tert. im Lichte der Jurisprudenz [Zeitschr. f. KG 27, 1907, 251 ff. 407 ff.]. 
zeichnete. Man wird dabei auch nicht übersehen dürfen, daß Tertullian nur aus der unsicheren Kunde eines Gerüchtes urteilte. Schon das audio, mit dem er. seine Mitteilung einleitete, und das bei einem so temperamentvollen Schriftsteller doppelt ins Gewicht fällt, hätte davor bewahren sollen, aus de pud. den wesentlichen Inhalt, ja gar einzelne Stücke in wörtlicher Anführung herauszuschälen. ${ }^{1}$ Wo und wie die Äußerung gefallen ist, läßt sich nicht mehr erklären. Es liegt nahe, an eine Predigt $z u$ denken, ${ }^{2}$ etwa über $\mathrm{Lk} 15$, in der sich eine solche Außerung fand, die dann Tertullian auf irgend einem Wege zu Ohren kam. ${ }^{3}$ Wenn er in der Schrift den Gegner häufig in der 2. Person anredet, so ist das ein so allgemeiner rhetorischer Brauch, daß man darüber gewiß nicht sonderlich in Aufregung zu geraten nötig hat.

Dem entspricht auch eine Vergleichung des Gedankenganges beider Schriften. Der Gegner, den der Montanist Tertullian in de pud. bekämpft, ist nicht nur der römische Bischof Kallist, sondern auch der vormontanistische Tertullian selbst. Die in de paen. c. 8 für die Möglichkeit einer zweiten, alle Sünden sühnenden Buße kehren sämtlich in de pud. wieder: 1) aus dem Wesen Gottes ergibt sich die Forderung der Milde [de pud. 2]: ille est, qui misericordian mavult quam sacrificia [de paen. 8, 3]. 2) Die Logik verlangt, daß der Buße Vergebung folge [de pud. 3]: non comminaretur autem non paenitenti, si non

$1 \mathrm{Vgl}$. Rolffs a. a. O. S. $103 \mathrm{ff}$.

2 Man beachte das concionari [13,7]: inque eum hominis exitum quantis potes misericordiae inlecebris bonus pastor et benedictus papa concionaris; und [17, 17]: quis seducit inanibus verbis quam qui concionatur remissibilem esse moechiam. DaB Kallist seine Anschauungen in Predigten vortrug, berichtet Hippolyt ganz ausdrücklich

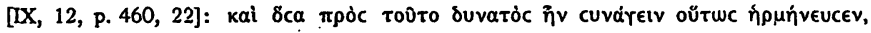

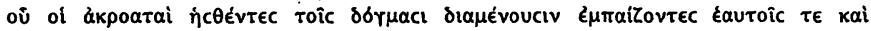

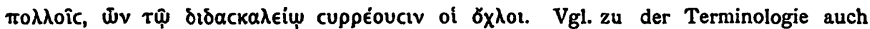
Kipp bei Pauly-Wissowa V, 1941, 5 ff.: „Der Akt des Edizierens ist ursprünglich die Verkündigung in contione durch den Magistrat oder seinen Herold. Diese Form wurde später meist durch den öffentlichen Anschlag ersetzt. " Man sieht, wie der Vorstellungskreis Tertullians durch die rechtlichen Formen umschrieben ist. Seiner Phantasie darf man das zugute halten; aber man sollte soviel Nüchternheit bewahren, um eine Ubertragung der Formen des Staatsrechtes auf die kirchliche Verfassung um 200 für unwahrscheinlich zu halten. Dann aber darf man-auch nicht von einem Edikte des Kallist sprechen.

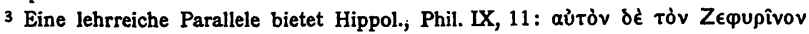

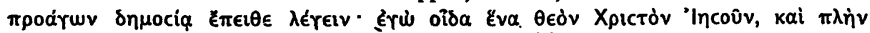

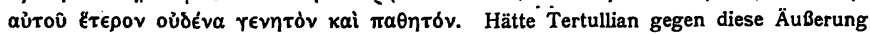
polemisiert, so würde er sie vielleicht auch als Edikt bezeichnet haben, formell mit

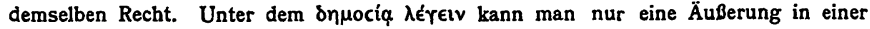
Predigt verstehen. 
ignosccret pacnitcrti [de paen. 8, 2]. 3) die Schriftstellen, die für Milde geltend gernacht werden können [de pud. 5-20]: hier werden besonders ausführlich dic de paen. 8, 4-8 angezogenen Gleichnisse Lk 15 behandelt; c. 19,1-6 die de paen. 8, 1 aus den Briefen der Apokalypse hergeleitcten Argumente widerlegt. Einem Rabulisten wie Tertullian konnte es nicht schwer fallen, seine eignen Gründe in das Gegenteil zu verkehren. Die exegetischen Kunststücke, die er macht, um z. B. die klaren Gedanken der Gleichnisse Jesu so zurechtzurücken, daß sie in seinen Beweis passen, lassen sich nur so verstehen, daß ihm hier die Wege gewiesen waren. Sie waren es tatsächlich durch seine erste Schrift, die von den Verteidigern einer größeren Milde gegenüber den groben Sünden leicht benutzt werden konnte und wohl auch tatsächlich benutzt worden ist. ${ }^{1}$

II.

Indem Tertullian die Äußerung Kallists als ein „peremptorisches“ Edikt bezeichnet, deutet er an, daß sie den Zweck hatte, eine Streitfrage endgültig zur Entscheidung zu bringen. Wann die Frage kontrovers geworden ist, läßt. sich daraus nicht entnehmen. Aber jedenfalls geht es nicht an, zu sagen, das Kallist nur die bereits bestehende und seither ohne Widerspruch geübte Praxis fortgesetzt und durch seinen Erlaß feierlich sanktioniert habe. Jedenfalls darf man dafür nicht das Zeugnis von de paenitentia geltend machen, das doch nur für Karthago oder die nordafrikanische Sitte maßgebend ist, nicht aber für die römische (s. o. S. 137). Ob diese mit jener übereinstimmte, bleibt Gegenstand der Untersuchung.

Für die Bußpraxis in Rom während des 2. Jahrhunderts bietet sich vor allem Hermas als Zeuge an. ${ }^{2}$ Er bezeugt mand. IV, 3, 1, daß das, was Tertullian de paen. 7, 2 u. ö. paenitentia secunda nennt, bestritten

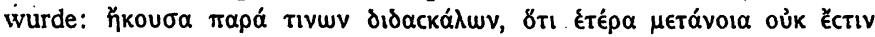

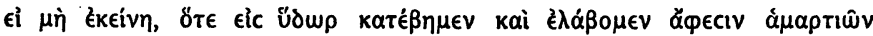

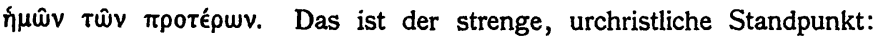

1 Den von F. X. Funk [Theol. Quartalschr. 1906, S. 541-568] unternommenen Versuch, nachzuweisen, daß Tertullian in de paen. hinsichtlich der Rekonziliation denselben Standpunkt vertrete wie in de pud., kann ich, trotzdem er manche Schwächen von Essers Bewveisführung gut aufzeigt, nicht für gelungen ansehen. Auch F. Loofs, Dogmengesch.4, 1906, S. 207 betont, daB in de paen. die Wiederaufnahme der Sünder in die Kirche vorausgesetzt sei.

2 Uber die Bußlehre des Hermas vgl. H. Windisch, Taufe u. Sünde i. ältesten Christentum, 1908, S. $356 \mathrm{ff}$. 
die Christen sind „vollkommen“ d. h. sie können, nachdem sie in der Taufe einmal Vergebung für die bis zur Taufe begangenen Sünden erhalten haben, nicht weiter sündigen, oder wie es Hermas ausdrückt:

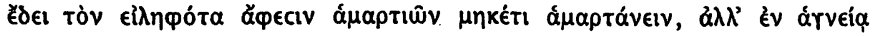
кaтoıkєiv [mand. IV , 3, 2]. Diesen rigoristischen Standpunkt bezeichnet Hermas ausdrücklich als richtig. $\mathrm{Da}$ sich aber zwischen Ideal und Wirklichkeit ein merkbarer Unterschied herausgestellt hat, die Christen, trotzdem sie theoretisch nicht mehr sündigen können, praktisch dennoch in Sünde verfallen, wie Hermas zu seinem Schmerz in seiner eignen Familie erleben mußte, so versucht er einen Ausgleich, indem er eine außerordentliche Sündenvergebung verkündigte, $\mathrm{zu}$ der er sich als durch eine besondere Offenbarung autorisiert erklärte.

Damit tritt Hermas tatsächlich dem rigoristischen Standpunkt, der eine Buße nach der Taufe überhaupt nicht anerkennt, entgegen: ${ }^{1} \mathrm{~W}$ as er verkündigt, ist die paenitentia secunda und er rechtfertigt sie mit demselben Gedankengang, den auch Tertullian, wahrscheinlich in direkter Abhängigkeit von ihm, befolgt: wenn jemand nach der Taufe vom Teufel versucht sündigt, so hat er noch eine Buße; sündigt er wiederholt und will er öfter Buße tun, so nützt ihm die Buße nicht mehr,

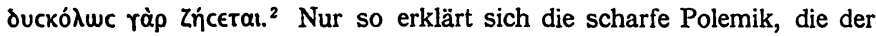
Montanist Tertullian gegen den Hirten des Hermas, den Pastor moechorum [de pud. 20,2] für notwendig erachtet hat. Ihn in de paen. zu zitieren, wie er es de or. 16 getan hatte, mochte aus Gründen unerlaubt sein, die auf dem kanonsgeschichtlichen Gebiete liegen. Das hinderte ihn aber nicht, seine Argumente zu akzeptieren und ihnen einen Schriftbeweis hinzuzufügen. Dennoch besteht ein wichtiger Gegensatz, der nicht übersehen werden darf. Die von Hermas verkündigte zwreite Buße gilt nicht schlechthin, sondern nur für eine bestimmte Zeit. Wenn jemand, nachdem dieser Tag festgesetzt ist, noch weiter sündigt, so hat er keine Vergebung mehr [vis. II, 2, 5]. Mit Recht macht Weinel ${ }^{3}$ auf

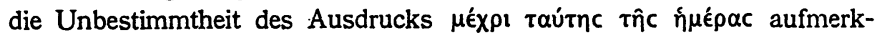
sam. Es wird wohl die Zeit gemeint sein, in der Hermas die Buße verkündigt, sodaß dem "heutigen Tage" einerseits der Tag der Taufe und andererseits der „jüngste Tag“ gegenübersteht. Dann hat Hermas aber nicht an eine Milderung der strengen Auffassung vom Wesen der Buße gedacht, sondern nur, bestimmt von eschatologischen und enthu-

1 Vgl. Th.Zahn; D. Hirte d. Hermas, 1868, S. 344 ff. Windisch a. a. O. S. $361.376 \mathrm{ff}$.

2 Hermas, mand. IV, 3, 6; vgl. Tert., de paen. 7, $7 \mathrm{ff}$.

3 Handbuch zu den ntl. Apokryphen, 1904, S. 296. 
siastischen Gesichtspunkten, von dem Rechte des Propheten Gebrauch gemacht und in einer besonderen Offenbarung den zahlreichen Sündern in der Gemeinde ${ }^{1}$ noch einmal eine außerordentliche Sündenvergebung angekündigt. $\mathrm{Da} B$ er damit nicht an eine dauernde Institution dachte,

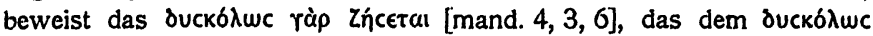

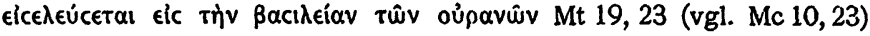
nachgebildet ist.

Daß diese Auffassung von der zweiten, außerordentlichen Bußverheißung verkehrt sei, hat Stufler an simil. IX, 20, 3 eingehend nachzuweisen gesucht. ${ }^{2}$ Er behauptet, daß nach der Bußfrist, die durch den Bußengel verkündigt werde, die Vergebung schwerer Sünden zwar aufhören solle, aber nicht absolut, sondern nur unter der Voraussetzung, $\mathrm{da} B$ das Ende der Welt nahe bevorstehe. $\mathrm{Da} B$ Hermas das Weltende nahe glaubte, ist selbstverständlich, wird außerdem ausdrücklich von ihm bezeugt [vis. III, 8, 9]. Die Frage, wie Hermas unter der Voraussetzung, daß das Weltende noch auf sich warten lassen werde, über die zweite Buße gedacht haben würde, ist müßig, und nur eine gerade Hermas gegenüber unerlaubte Dialektik kann behaupten, daß die einmalige Sündenvergebung nicht absolut ${ }^{*} z u$ verstehen sei. Für Hermas kommt ein anderer Gesichtspunkt gar nicht in Betracht, und eine Erörterung darüber, ob seine Behauptungen von ihm absolut oder bedingt gemeint seien, führt $\mathrm{zu}$ keinem Ziel. $^{3}$

Auch darin wird man Stufler nicht beistimmen können, wenn er meint, daß die von Hermas verkündigte Buße die kirchliche Rekonziliation und Wiederaufnahme einschließe. $\mathrm{Daß}$ für Hermas die reuigen Sünder zu dem Turm d. h. zu der. "Kirche“ gehören, ist offenbar [vis. III, 3, 6 ff. sim. IX, 7, 1]. Stufler hat ganz recht, wenn er sagt, daß von Hermas S. IX, 14, 2 deutlich die Wiederaufnahme der reuigen Sünder in die Kirche ausgesprochen werde. $\mathrm{Da}$ sie nun in dieselbe Kirche zurückkehren, in der sie sich bereits früher befanden, so müsse demnach die sichtbare Kirche auf Erden gemeint sein. Man kann den Vordersatz sehr wohl zugeben, ohne den Nachsatz ebenfalls als berechtigt anzuerkennen. Denn.es ist eben doch die Frage, ob Hermas zwischen sichtbarer und unsichtbarer Kirche ebenso schied, wie Stufler, oder ob ihm nicht der Begriff der empirischen Kirche mit ihren Vor-

1 Vgl. die instruktive Zusammenstellung bei Weinel in Henneckes Apokryphen des NT. 1904, S. 220 f. J. Stufler, Ztschr. f. kath. Theol. 31, 1907, S. 454 ff.

2 Ztschr. f. kath. Theol. 31, 1907, 8. 454-473; vgl. auch 32, 1908, 537 ff.

3 Richtig gewertet ist das eschatologische Moment im Hermas bei $\mathrm{H}$. Windisch a. a. O. S. 359. 
stehern [vis. II, 4, 3. III, 9, 7] und ihren Verächtern [sim. VIII, 6, 4] zusammenfloß mit dem Begriff des Reiches Gottes. Seine Äußerungen

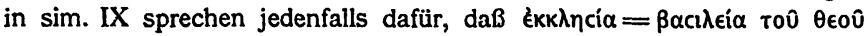

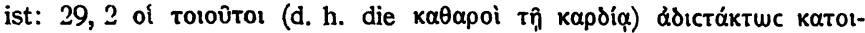

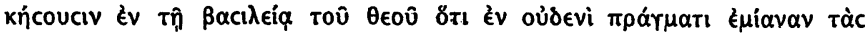

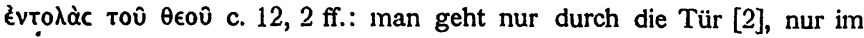
Besitz des Namens (d. h. getauft) [3] in das Reich Gottes. Diejenigen, die in es eintreten, sind aber diejenigen, die den Turm bewohnen. Im Gottesreich wird nur erfunden, wer mit dem Gewande des heiligen Geistes bekleidet ist $[13,2]$ und neben dem Namén Jesu auch mit dem der christlichen Tugenden geschmückt ist $[15,2]$. Kirche und Reich Gottes sind also für Hermas identische Begriffe, und nur so geschieden, daß jene die empirische, dieses die transzendente Seite derselben Erscheinung bezeichnet. Das ist genau der Standpunkt des Urchristentums. ${ }^{1}$

Noch weniger überzeugend ist die These Stuflers, daß es auch vor Hermas schon eine zweite Buße gegeben habe, daß somit seine Offenbarung gar nichts Neues gebracht habe. Warum in aller Welt, so fragt man doch gegenüber dieser Behauptung, hat dann aber Hermas überhaupt eine solche Offenbarung für nötig erachtet und diese Offenbarung noch dazu in diese seltsam feierliche Form gekleidet, da $3 \mathrm{ihm}$ zunächst nur der von ihm vorderhand nicht verstaridene Wortlaut „Buchstabe für Buchstabe" mitgeteilt und dann wiederum der Sinn durch besondere Offenbarung erschlossen wurde? Man braucht die geistigen Qualitäten des Hermas nicht allzu hoch einzuschätzen, auch seinem Gesichtskreis keine übermäßige Weite zuzugestehen; aber eine solche Absurdität ihm zuzutrauen liegt denn doch kein Grund vor. Es wäre doch psychologisch einigermaßen rätselhaft, wie Hermas darauf verfallen sein sollte, einer schon längst bestehenden Anschauung, die bereits $\mathrm{zu}$ einer festen kirchlichen Sitte geführt hatte, gleichsam nachträglich die Sanktion einer pneumatischen Offenbarung zu geben. Man würde auch schwerlich auf diese Meinung verfallen sein, wenn nicht jene Äußerurig [mand. IV, 3, 1] von den rigoristischen Lehrern, deren Ansicht Hermas ziwar theoretisch billigt, in praxi aber bekämpft, dazu

1 Vgl. R. Sohm, Wesen u. Ursprung d. Katholizismus [Abh. d. sächs. Ges. d. Wiss., phil.-hist. Kl. XXVII, 1909], S. 357: „Die Urzeit hat den Begriff einer rechtlich verfaßten Kirche nicht gehabt. Sie hatte nur den Begriff der Christenheit, und zwar der Christenheit als einer religiösen Größe. ${ }^{\alpha}$ Daher laufen bei Hermas in der Vision

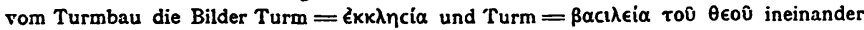
über. Eine klare Scheidung wird man vergeblich versuchen. 
verlcitet hätte. Sie hat auch sonst mancherlei Unheil angerichtet, sogar neuerdings zu einem Datierungsversuch herhalten müssen. ${ }^{1}$ Aber es ist doch zu fragen, ob Erwähnung jener Lehrer wirklich imstande ist, ein so schweres Gewicht zu tragen. Hermas braucht den Ausdruck

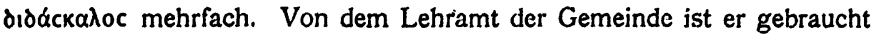

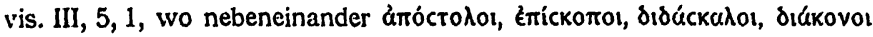

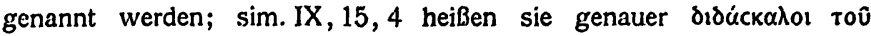

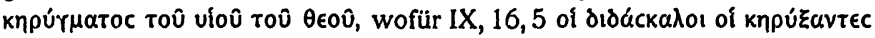

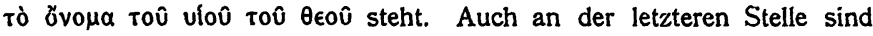
sie neben die Apostel gestellt und bilden sinngemäß mit diesen eine besondere Gruppe. Daß der Begriff in der Tat nicht weit von dem der

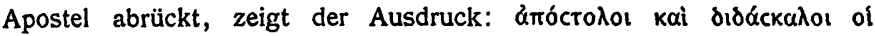

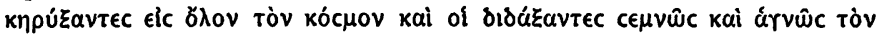

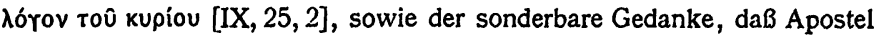

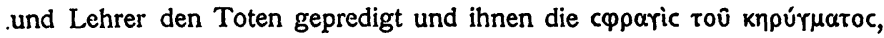
d. h. die Taufe erteilt haben, damit auch sie in das Gottesreich eingehen können [s. IX, 16,5].

Unter diesen Umständen ist es durch nichts zu erweisen, daß die

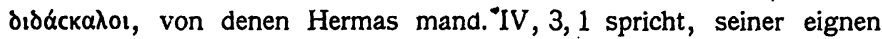
Generation angehören, und daß er die rigoristische Auffassung vom Wesen der Buße unmittelbar von ihnen selbst vernommen habe. Es können längst verstorbene Lehrer sein, deren Wort als autoritativ gilt. Der Sprachgebrauch steht jedenfalls einer solchen Auffassung nicht im Wege, wennschon dann der Gedanke deutlicher so ausgedrückt wäre:

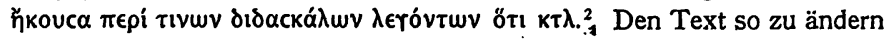
wäre graphisch leicht, könnte auch durch den Umstand gestützt werden, $\mathrm{da} \beta$ der Lateiner $\lambda \in$ róvtwv gelesen $\mathrm{zu}$ haben scheint. ${ }^{3}$ Aber $\mathrm{zu}$ einer

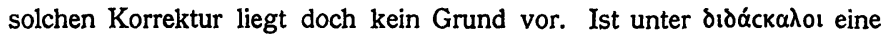
mit den Aposteln enge zusammengehörige Gruppe von Verkündigern des Evangeliums gemeint, so kann Hermas bei seinen Worten sehr

1 A. Stahl, Patrist. Untersuchungen, 1901.

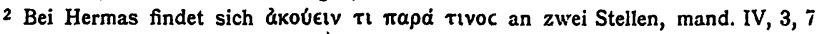
und sim. 5, 4, 2, beide Male in der Bedeutung, "etwas von jemanden unmittelbar hören ${ }^{\alpha}$. Sonst wird das sachliche Objekt meist durch den Akkusativ, die Person, von der man etwas hört, meist durch den Genitiv ausgedrückt. Doch ist der Sprachgebrauch des Hermas keineswegs konstant. Die lateinische Obersetzung hat übrigens sim. V, 4, 2 die Worte rapd cou übergangen.

$3 \mathrm{Er}$ übersetzt: audivi quosdam' magistros viae nostrae dicentes, non esse alc. $\mathrm{Ob}$ das viae nostrae wirklich auf eine Vorlage zurückweist, muß unentschieden bleiben. Clemens Alex., der Strom. II, 56, 1 die Stelle des Hermas ausschreibt, hilft nicht weiter, da bei ihm 3, 1 fehlt. 
wohl an Hebr 6, 4ff. gedacht haben. Überträgt man die feierlichen Aus-

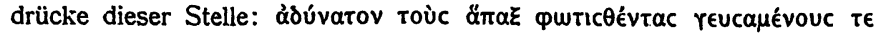

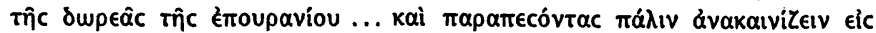

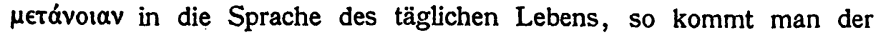

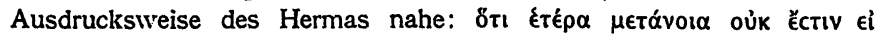

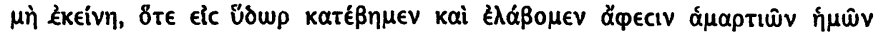

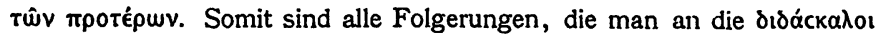
und ihre Lehre geknüpft hat, hinfällig. Es sind weder Montanisten, noch Vorläufer des Montanismus, und dem Hermas selbst lassen sich auf Grund dieser Stelle weder montanisierende noch antimontanistische Tendenzen nachweisen. Vielmehr ist er auch hier ein Vertreter der Übergangszeit vom Urchristentum zur altkatholischen Kirche.

Man wird demnach bei Hermas auch keine Spuren einer Bußdisziplin, eines Bußaktes und einer feierlichen Wiederaufnahme des reuigen Sünders in die Gemeinde zu finden erwarten können. Stufler fordert das von seinem Standpunkte aus, ohne einen Beleg für die Behauptung $\mathrm{zu}$ bringen. ${ }^{1}$ Die Gemeinde ist ideell die Vereinigung der Vollkommenen, d. h. derjenigen, die getauft sind und heilig leben. Praktisch war freilich ein wahrnehmbarer Abstand von dem Ideal. Daher verkündigte Hermas als Prophet eine nochmalige Bußfrist; war sie abgelaufen, so sollte die Sünder rettungslos ihr Schicksal ereilen.

Aus Justin, den man für die römische Praxis wohl kaum als unbedingt gültigen Zeugen anrufen kann, ergibt sich nichts für die Frage. Wenn er Dial. 141 p. 370D den Juden gegenüber betont, daß nur der Bußfertige Vergebung empfange, daß aber nicht, wie es jüdische Lehre sei, der Glaube an Gott zur Seligkeit genüge, möge der Gläubige auch ein Sünder sein, so geht daraus nicht hervor, welche Buße er damit gemeint habe. Der von ihm beigebrachte Hinweis auf Davids Fall und Buße [p. 371 A] führt nicht.weiter. Daß auch Irenäus nicht als Vertreter einer zweiten Buße mit darauffolgender Rekonziliation angesehen werden dürfe, hat Koch in dieser Ztschr. [1908, S. 35-46] so überzeugend nachgewiesen, daß ein erneutes Eingehen auf diese Frage nicht nötig ist. ${ }^{2}$.

Steht nun schon somit die Sache derer sehr ungünstig, die der Ansicht sind, daß Kallist mit seinem Vorgehen keinerlei Neuerung ge-

1 Ztschr. f. kath. Th. 31, 1907, S. 459.

2 Die Einwendungen, die Stufler [Ztschr. f. kath. Theol. 1908, S. 488-497] dagegen erhoben hat, geben mehr von dogmatischen als von historischen Gesichtspunkten aus und können daher hier auf sich beruhen. Vgl. auch Windisch, Der Christ u. d. Sünde, S. $409 \mathrm{ff}$. 
schaffen habe, sofern sich nachweisen läßt, daß in dem zweiten Drittel des 3. Jahrhunderts in Rom von einer Milderung der kirchlichen Sitte nicht die Rede sein kann, so wird sie vollends unglaubhaft durch die Tatsache, daß in dem letzten Drittel des 2. Jahrhunderts in Rom die Stimmung für den Montanismus günstig war, so daß nur wenig an einer offiziellen Anerkennung der phrygischen Prophetie fehlte. Daß um 180 die montanistische Bewegung auch in Rom zu einer Beunruhigung der Gemüter geführt hatte und daß daher die gallischen Märtyrer sich veranlaßt sahen, an Eleutherus zu schreiben, geht aus Euseb., h. e.V,4,1 f. hervor. In welchem Sinn der Brief gehalten war, dessen Anfang hier mitgeteilt ist, zeigt 3, 4. Die Märtyrer redeten zum Frieden, empfahlen also in Rom wie in Phrygien und Asien eine den Montanisten entgegenkommende Haltung. ${ }^{1} \mathrm{Ob}$ mit diesen Erörterungen auch die Angelegenheit des Monarchianers Praxeas zusammenhängt, der einen nicht genannten römischen Bischof davon abhielt, die bereits beschlossene Gemeinschaft mit den Montanisten wieder aufzuheben und die schon erlassenen litterae pacis zu revozieren [adv. Prax. 1], ist unsicher. ${ }^{2}$ Fällt diese Episode unter. Eleutherus, wofür.man sich auf Euseb., h. e. V, 4 berufen kann, so ließe sich der Verlauf so denken, daß der römische Bischof den in Kleinasien heftig bekämpften Montanisten gegenüber eine freundliche Haltung einnahm, dann aber von Praxeas umgestimmt wurde, seine Briefe widerrief und so die Kontroverse derart verschärfte, daß sich die gallischen Märtyrer durch einen Brief für den kirchlichen Frieden verwandten. Wahrscheinlicher ist es aber, daß es Victor war, der den Montanisten soweit entgegenkam, da er wegen der quartodezimanischen Ostersitte mit den kirchlichen Kreisen Kleinasiens in Konflikt geraten war, ihm also die Bundesgenossenschaft der Montanisten willkommen sein mußte, da diese ebenfalls das Osterfest nicht am 14. Nisan feierten, sondern an dem auf den 14. des 7. Kleinasiatischen Monats folgenden Sonntag. ${ }^{3}$. Deckte sich das auch nicht mit der römischen Observanz, für die Victor, zugleich im Interesse der Suprematie des römischen Stuhles kämpfte, so war es doch für diesen ein will-

1 Th. Zahn, Forschungen V, 43 ff. G. H. Voigt, Eine verschollene Urkunde d. antimont. Kampfes, 1891, $71 \mathrm{ff}$.

2 Für Eleutherus ist besonders Bonwetsch, Gesch. d. Montanismus, 1881, 140. 174 eingetreten. Auch Harnack hält die Identifizierung für wahrscheinlich, Chronol. d. altchr. Lit. I, 375 f. Real-Enzykl. ${ }^{3} 13,328,2$. Zahn [Forschungen V, 49] hält mit Voigt a. a. 0.71 nach Ps. Tertull., adv. omn. haer. 25, der den Bischof Victorinus nennt, Victor für den von Tertullian adv. Prax. genannten Bischof.

3 Vgl. Ed. Schwartz, Christl. u. jüd. Kalendertafeln [Abh. d. Gött. Gesellsch. d. Wiss., phil.-hist. Kl. VIL, 6], 1905, S. 104 f. 
koimmenes Argument gegen die von den Kleinasiaten behauptete Gleichförmigkeit der Überlieferung ihres Brauches von den Zeiten der Apostel an. Denn auch die Montanisten werden sich auf die urchristliche Überlieferung berufen haben, indem sie einfach den 7. Monat mit dem jüdischen Nisan gleichsetzten. ${ }^{1}$ Mag nun in diesem Fall auch die Anerkennung des Montanismus nur eine Phase der kirchlichen Politik gewesen sein, so ist dóch kaum denkbar, daß zu derselben Zeit eine Milderung der Bußpraxis eingetreten sein sollte. Zwischen dem Tode Victors und dem Episkopat des Kallist liegen nur $18 \mathrm{Jahre,} \mathrm{aus} \mathrm{denen} \mathrm{wir} \mathrm{freilich} \mathrm{über}$ die Politik des römischen Bischofs nichts erfahren.

Somit war es in der Tat eine Neuerung, wenn Kallist nun, den Anschauungen, die seither gegolten hatten, entgegentretend, auch für die schweren Sünden wenigstens insoferne eine Erleichterung einführte, $\mathrm{daß}$ er die Unzuchtsünden herausnahm und wenigstens diese für vergebbar erklärte. Dunkel bleibt nur noch, wie es dazu kam, daß man unter den groben Sünden gerade die drei als die gröbsten und darum in keiner Weise $z u$ vergebenden herausgriff. In de paen. liegt keine Andeutung vor, daß man eine solche Scheidung bereits vollzogen hatte. Wäre es der Fall gewesen, so würde Tertullian seine Begründung der zweiten Buße gewiß nicht mit einem Hinweis auf die Briefe des Apokalyptikers begründet haben. Für Tertullian muß also die Erkenntnis, $\mathrm{da} \beta$ bestimmte Sünden als Todsünden eine besondere Stellung einnehmen, erst nach der Abfassung von de paen. aufgegangen sein. $\mathrm{Da}$ er von seinem montanistischen Standpunkt als solche Sünden, für die keine Vergebung möglich ist, folgende bezeichnet (de pud. 19, 24): homicidium, idololatria, fraus, negatio, blasphemia, moechia, fornicatio et si qua alia violatio templi dei, ${ }^{2}$ so wird man nicht sagen dürfen, daß die Kasuistik schon zu einer genauen Abgrenzung dessen gekommen war, was als Todsünde zu gelten hatte und demnach von der Vergebung ausgeschlossen bleiben mußte.

An einigen Stellen erweckt aber Tertullian in seiner montanistischen Schrift den Anschein, als ob er bei den Todsünden zwar von seinem-montanistischen Standpunkt an eine größere Anzahl von crimina denke, während von der Kirche die drei, Mord, Ehebruch, Götzendienst allein als unvergebbar bezeichnet würden. Die Erörterung

1 Schwartz a. a. O. S. 33.

2 Vgl. auch die Liste c. 9, 9: moechi, fornicatores, idololatrae, blasphemi, negatores et omne apostatarum genus. adv. Marc. IV, 9: idololatria, blasphemia, homicidium, adulterium, stuprum, falsum testimonium, fraus. In der letzteren Zusammenstellung macht sich der EinfluB des Dekalogs deutlich bemerkbar. 
über das Apostelkonzil und den dort gefaßten Beschluß [de pud. 12] beschließt Tertullian mit folgendem Gedankengang: die Apostel erleichterten die andern Lasten des Gesetzes, um desto energischer auf das Notwendigste hinzuweisen. Sie befreiten von dem Joche des Gesetzes, um dafür die Disziplin desto fester zu handhaben; solverunt a pluribus, ut nocentioribus observandis obligaremur. Solange nun das Aposteldekret in der Kirche verlesen wird, muß auch die dadurch geschaffene Verpflichtung bestehen bleiben: hinc est quod neque idololatriae neque sanguini pax ab ecclesiis redditur. Es soll damit schwerlich gesagt werden, daß nur diese beiden Delikte von den Gemeinden allgemein als unsühnbar betrachtet würden. Vielmehr ist die Erörterung nur im Zusammenhang mit der Behandlung des Aposteldekretes zu verstehen. Eine Andeutung über die bestehende Disziplin und die Grundsätze bei der Beurteilung der Sünde ist kaum darin zu erblicken.

Somit ergibt sich, daß3 die Kasuistik hinsichtlich vergebbarer und unvergebbarer Sünden eben erst beginnt und daß sie in montanistischen Kreisen zuerst ausgebildet wurde. In den Gemeinden entschied wohl nur das Herkommen. Schwere Verbrechen waren von der Buße ausgeschlossen. Dazu gehörten nicht nur Apostasie und Mord, sondern, wie man aus der Darstellung Hippolyts hinsichtlich Kallists entnehmen kann, in Rom zur Zeit Victors auch Betrug und Unterschlagung. Hippolyt hat die Sache freilich in seiner Weise zurechtgestutzt. Er erzählt [IX, 12 p. 456], daß Victor auf der. Liste der zu befreienden Märtyrer den Namen des Kallist weggelassen habe. Da Kallist, wie S. $140^{2}$ gezeigt wurde, wegen seines Vergehens von der Gemeinde ausgeschlossen war, erfolgte die Weglassung durchaus mit Recht. Andererseits betrachtete sich Kallist ebenfalls als Märtyrer, und er galt als solcher, ${ }^{1}$ denn er war ja nicht wegen seines Bankerotts bestraft worden, sondern auf die Anklage der Juden hin als Christ. So wird wohl auch der Presbyter. Hyakinthus, der den Brief des Bischofs zugleich mit dem von Marcia erwirkten Freilassungsbefehl nach Sardinien überbrachte, die Sache angesehen und darum auch die Freigabe des scheinbar übersehenen Märtyrers bewirkt haben. Victor war die Sache unangenehm

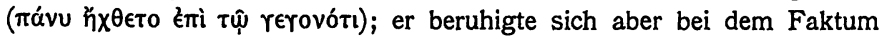
und sorgte nur dafür, daß Kallist von Rom wegkam, um keinen Anlaß zu allerlei Vorwürfen $\mathrm{zu}$ geben und zugleich, weil Karpophorus von dieser Entwicklung der Dinge nichts wissen wollte. ${ }^{2}$ So wurde er nach

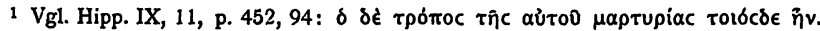

2 Der letztere Grund ist undurchsichtig. Karpophorus als Besitzer des Kallist hatte sich vorher der Verbannung zu widersetzen gesucht, doch ohne Erfolg [p. 454, $37 \mathrm{ff}$.] 
Antium geschickt, wo ihm Victor ein Monatsgeld für seinen Unterhalt anwies.' Sein Martyrium hatte alle Schuld gesühnt, so daß man ohne Bußakt Kallist stillschweigend wieder als Glied der Kirche duldete. - Aber das anfängliche Sträuben Kallists und die Furcht vor Vorvürfen zeigen, daß die Behandlung des ganzen Falles dem sonst Üblichen widersprach.

\section{III.}

Die Frage nach der Behandlung grober Sünder bildete um die Wende des 2. Jahrhunderts einen Gegenstand erns̈ter Erwägung für die Christen. Es war für sie nicht nur eine praktische Frage, die mit den Mitteln kirchlicher Disziplin gelöst werden konnte, sondern auch eine dogmatische, von deren Entscheidung die praktische Haltung abhängig gemacht werden mußte. Den Standpunkt, den Tertullian in de paenit. vertrat, präzisiert Clemens Al., Strom. II, 57 mit diesen Worten:

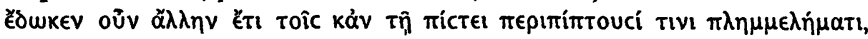

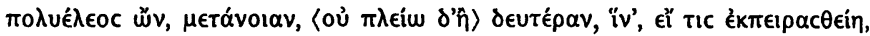

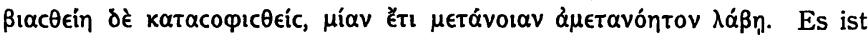
im wesentlichen auch der Standpunkt des Hermas, nur daß das, was bei diesem zeitlich beschränkt blieb, verallgemeinert wurde. Der rigoristischen Auffassung, die hierdurch als die herrschende erwiesen wird, wollte Clemens auch durch die Erzählung von Johannes und dem Jüngling entgegenwirken [qui dives salv. 42], deren Sinn durch Schwartz klargestellt worden ist. ${ }^{2}$ Sie soll zeigen, daß auch dem Sünder, wenn er Buße tut, noch die Hoffnung auf die Rettung bleibt, weil für ihn die Verzweiflung das Schlimmste ist und die Hoffnungslosigkeit ihn unbedingt zur Verzweiflung führen muß. So bewirkt denn Johannes, daß der Verzweifelte Hoffnung schöpft und überläßt das weitere der Gemeinde, ${ }^{3}$ die aus dem Verhalten des Johannes die praktischen Folgen zu ziehen hat.

Hippolyt läßt nicht erkennen, warum er sich den neuerlichen Maßregeln Victors widersetzte.

1 Wenn das eine Art Verbannung darstellte, so konnte Kallist damit schon zufrieden sein. Antium war ein bevorzugter Villenort der vornehmen Römer: vuvi $\mu e^{\prime} v$

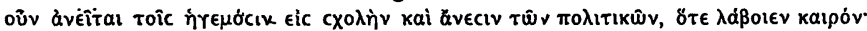

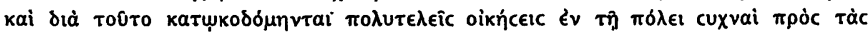

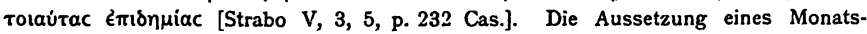
gehaltes ist jedenfalls so. $\mathrm{zu}$ verstehen, $\mathrm{da} B$ er dort als Kleriker fungierte. Daß er bei seiner Rückkehr nach Rom Diakon war, ist sicher, s. K. J. Neumann, D. röm. Staat u. d. christl. Kirche I, .1890, S. $107^{3}$.

2 Hermes 38, 1903, S. 82.

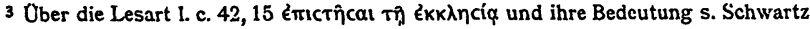
a. a. O. S. 82.

Zeitschr. f. d. neutest. Wiss. XI. Jahrg. 1910. 


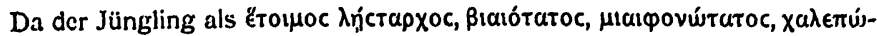
Tatoc bezeichnct ist $[42,7]$, so ist deutlich, in welcher Richtung sich die Gedanken des Clemens hinsichtlich der groben Sünden bewegen. Auch dem Todsünder soll man nicht die Buße unmöglich machen, und wenn er Buße tut, soll ihn die Gemeinde nicht vor der Türe stchen lassen. Aber es ist bezeichnend, daß Clemens, worauf Schwartz nachdrücklich hingewiesen hat, von einer Vergewaltigung der Gemeinde nichts weiß. Nicht Johannes nimmt den Sünder wieder auf, sondern er bringt ihn zur Reue, stellt ihn dann der Gemeinde vor und geht danach davon. Das entspricht seiner Auffassung von dem seelsorgerlichen Charakter des Gnostikers. ${ }^{1}$

Die Neuerung, die Kallist einführte, bestand also nicht sowohl darin, daß er in der Beurteilung der Unzuchtsünden eine mildere Praxis einschlug, sondern vor allem darin, daß er das Recht zu dieser Praxis kraft seines bischöflichen Amtes und auf Grund seiner apostolischen Autorität für sich in Anspruch nahm. So verstand man wenigstens in der Kirche das Vorgehen Kallists und versäumte nicht, dagegen scharfen Protest zu erheben. In seiner bald nach 230 geschriebenen Schrift "vom Gebet" $[28,10]$ sagt Origenes mit deutlicher Anspielung auf die Maßregeln des römischen Bischofs: ${ }^{2}$ oủk oỉ $8 \pi \omega c$ Eautoîc tivec

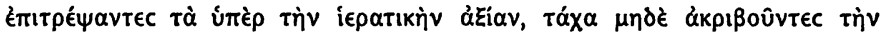

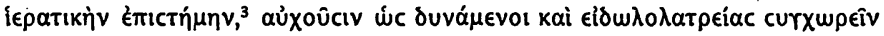

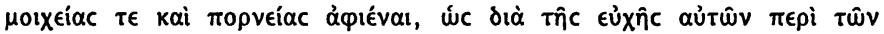

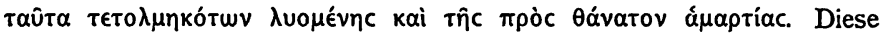
Notiz ist aus mehreren Gründen wichtig. Sie beweist, daß sich die Milde nicht nur auf die Unzuchtsünden erstreckte, sondern auch auf die Idololatrie ausgedehnt wurde, und zweitens, daß die Gemeinde vollständig zurücktrat und an ihre Stelle das wirkungskräftige Gebet des Amtsträgers gesetzt wurde. Das ist ein Fortschritt auch über den von Tertullian, de paen. 9 beschriebenen Bußakt, bei dem der Bischof gar nicht hervortritt, sondern nur die Presbyter, die cari dei, d.h. die Mär-

1 Vgl. K. Holl, Enthusiasmus und Bußgewalt, 1898, S. $226 \mathrm{ff}$.

2 Origenes ist unter Zephyrin in Rom gewesen [Euseb. VI, 14, 10], allerdings nur für kurze Zeit. Die Entwicklung der Dinge, die sich damals bercits anbahnen mochte, konnte er. dann auch von Alexandria aus verfolgen.

. 3 Diese Worte erinnern auffallend an Hippolyts Charakteristik des Zephyrin:

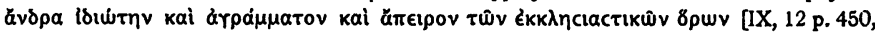
6850]. Aber sie können auch auf Kallist passen, der zwar ein äußerst weltkundiger

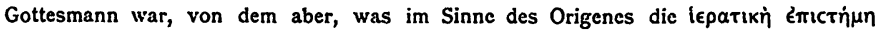
ausmachte, wenig genug besaß. 
tyrer, ${ }^{1}$ und die gesamte Brüderschaft genannt werden. Das Gebet, das Gott versöhnt, ist das Gebet der Gemeinde und der "Geehrten " in der Gemeinde, vor allem der Geistträger, nicht das der Bischöfe.

Gegen den Geist, dem diese Neuerung entsprang, richtete Tertullian in erster Linie seine Polemik. Daher der bittere Sarkasmus, mit dem er den Bischof überschüttete und der in dem spöttisch gewählten Titel Pontifex Maximus zum Ausdruck kommt. Der Titel, seit Augustus üblicherweise ein Teil der kaiserlichen Würde, hatte, zwar zur Zeit Tertullians faktisch keine besondere Bedeutung mehr; aber rechtlich stand dem Pontifex maximus als dem Präsidenten des Priesterkollegiums nicht nur die Ausführung der von diesem gefaßten Beschlüsse zu, sondern er hatte auch das Recht der Entscheidung in Fällen, die keinen Aufschub gestatteten. ${ }^{2}$ Auf dies Recht spielt Tertullian mit seinem Ausdruck edictum peremptorium an. Wenn er dem ironisch gemeinten Titel den andern episcopus episcoporum zufügt, so hat er sich damit wohl einem tatsächlich bestehenden Brauch angeschlossen, der auch von Cyprian bezeugt wird, wenn er in den Akten des Konzils von Karthago in Sachen der Ketzertaufe sagt: ${ }^{3}$ neque enim quisquam nostrum episcopus se episcoporum constituit aut tyrannico terrore ad obsequendi necessitatem collegas suos adigit, quando habeat onmis episcopus pro licentia libertatis et potestatis suae arbitrium proprium tamque iudicari $a b$ alio non possit, quam nec ipse possit alterum iudicare. 'Aber das Bezeichnende an diesem Sprachgebrauch war eben die Steigerung des Amtsbewußtseins, die in der Form des „Ediktes“ deutlich zum Ausdruck gebracht ist. Wie Zephyrin in den monarchianischen Wirren dekretierte:

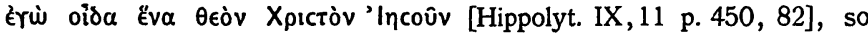
dekretiert Kallist ego et moechiae et fornicationis delicta paenitentia functis

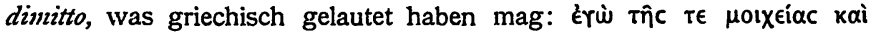

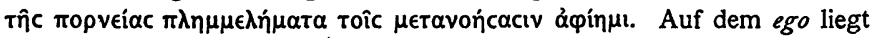
der Nachdruck und hierin besteht die Neuerung.

Der Bestreitung dieses Anspruches hat denn auch Tertullian noch einen besonderen Abschnitt gewidmet [de pud. c. $21 \mathrm{f}$.]. Er beschränkt das Bịschofsamt auf die Disziplin und verlangt für die Befugnis, Sünden zu vergeben, Beweise prophetischer Gaben, d. h. Beweise für den Geistes-

1 Zur Geschichte dieses Begriffes vgl. K. Holl, Enthusiasmus und BuBgewalt S. 1291. Daß die Form des Bußaktes zunächst nicht geändert-wurde, ist selbstverständlich und wird von Tertullian [de pud. 13,7] ausdrücklich bezeugt.

2 Vgl. G. Wissowa, Religion und Kuitus der Römer, 1905, S. 437 ff.

3 Vgl. H. v. Soden, Sententiae LXXXVII episcoporum [Nachr. d. K. Ges. d. Wiss. zu Göttịngen, philol. hist. Klasse, 1909], S. 249, 1 ff. 
besitz. Mit diesem extrem urchristlichen Argument weist Tertullian auch den Einwand zurlick, daß doch auch die Gemeinde das Recht der Sündenvergebung besitze. ${ }^{\perp}$ Wenn er sich demgegenüber auf den Ausspruch des Montanus beruft: potest ecclesia donare delicta, sed non faciam ne et alia delinquant [21,7], so ergibt sich daraus für die Montanisten der Gemeindebegriff, den Tertullian 21, 17 in klassischer Weise so formuliert hat: ecclesia delicta donabit, sed ecclesia spiritus per spiritalem hominem. Gemeinde ist ihm Geistesgemeinde und darum ihr berufener Vertreter der Geistbegabte. Ihr stellt er schroff gegenüber die Gemeinde, deren Vertreter der Bischof ist, als deren Organ dieser die Vergebung der Sünden vollzieht: ecclesia numerus episcoporum, die Gemeinde, die von der Synode der Bischöfe repräsentiert wird. Die Polemik ist verständlich, wenn man erwägt, welchen Eifer die kleinasiatischen Bischöfe entfaltet haben, um den Montanismus zu unterdrücken. Aber auch in Rom gewann der Bischof jedenfalls seit Victor einen steigenden Einfluß, und diese Politik setzte Kallist fort.

Von hier aus fällt auch Licht auf einige Bemerkungen Hippolyts [IX, 11 p. 450, 68ff.] über die Folgen des Einflusses, den Kallist auf Zephyrin gewann. Zephyrin, der gan $\dot{z}$ ungebildet war und von den kirchlichen Bestimmungen nichts verstand [s. S. $154^{3}$ ], geriet in vollständige Abhängigkeit von dem verschlagenen und geschäftsgewandten Kallist, der bei den in der großen Gemeinde jedenfalls recht schwierigen Finanzverhältnissen eine willkommene Stütze sein mußte; ĕ $\pi \in t \theta \in v$

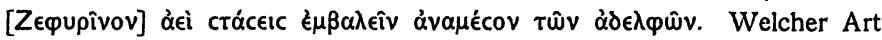
diese Streitigkeiten waren verrät Hippolyt nicht. Aber er scheint es an einer anderen Stelle anzudeuten [IX, 12 p.456, 64f.]: $\mu \in \theta^{\prime}$ oũ [Oúíkтороc]

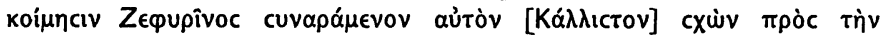

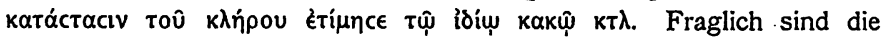

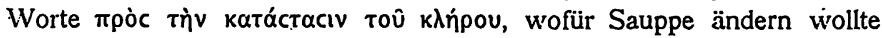

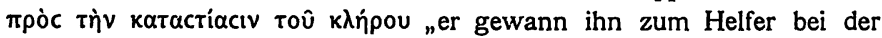
Unterdrückung des Klerus".2 Auch das könnte ja in der Gemeinde zu Unruhen geführt haben. Erinnert man sich aber der Kämpfe, die schon

1 Man wird auch in diesem Einwand einen weiteren Grund sehen dürfen, der es verbietet, die von Tertullian bekämpiten Argumente als Reste des „Ediktes“ aufzufassen. Kallist kann von seinem Standpunkt gar nicht den Satz ausgesprochen haben: potest ecclesia donare delictum, da er diese Befugnis dem Amt und seinem Träger zuschreibt. An der Stufenleiter Geistträger - Gemeinde - Amt ist Kallist auf der obersten Stufe angekommen. Tertulian erkennt nur die erste an und repristiniert somit die urchristliche Auffassung.

2 Danach übersetzen Duncker und Schneidewin ad reprimendum clerum, was dem von ihnen gebotenen griechischen Text nicht entspricht. 
zu Hermas Zeiten zwischen dem Klerus und den Pneumatikern in der Gemeinde geführt wurden [mand. $\mathrm{XI}$ ], ${ }^{1}$ so wird man den überlieferten Text beibehalten und es für möglich halten dürfen, daß diese Kämpfe auch unter Zephyrin noch nicht zur Ruhe gekommen waren, und daß Hippolyt sagen will: Kallist habe den Bischof in seinem Kampf für die Etablierung des Klerus über der Gemeinde unterstützt, also für Rom den Zustand zum Abschluß bringen helfen, den Origenes [in Mt XVI, 22;

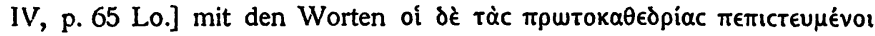

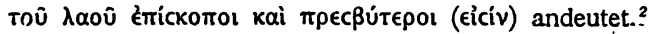

- Da Tertullian den Kirchenbegriff des Kallist, nach dem ecclesia die rechtlich verfaßte Organisation ist, ablehnt und für die Gemeinde nur das Moment des Geistesbesitzes anerkennt, muß er sich auch gegen die Auslegung des Wortes Mt 16,18f. wenden, aus der für diese Gemeinde die Binde- und Lösegewalt gefolgert und somit den Bevollmächtigten dieser Gemeinde, den Bischöfen zugeschrieben wurde [21, 9 ff.]. Von dieser Verwertung des Jesuswortes im Sinne der bischöflichen Binde- und Lösegewalt spricht auch Origenes in dem Kommen-

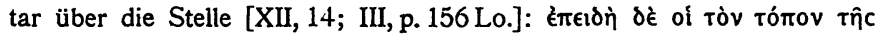

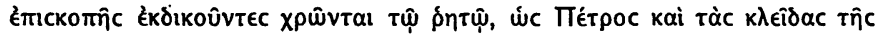

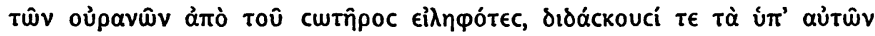

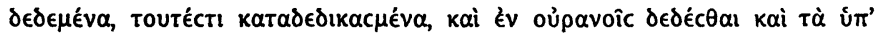

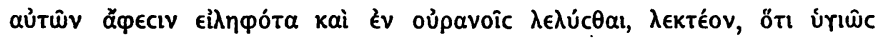

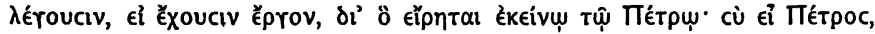

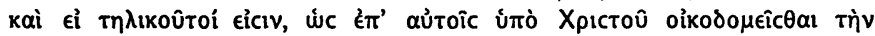

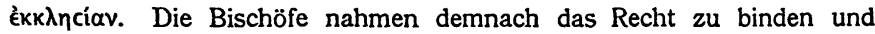
zu lösen in Anspruch, indem sie so argumentierten: Petrus hat das Recht erhalten, auf Petrus ist die Kirche gebaut; folglich hat die Kirche dasselbe-Recht und sie übt es durch die Bischöfe aus. Origenes gesteht den Bischöfen das Recht auch $z u$, wenn bei ihnen die Voraussetzung erfüllt ist, die bei Petrus gegeben war. Das trifft im wesentlichen auch mit der Argumentation Tertullians zusammen. Wichtig ist hierbei, daß wir aus Origenes die Betveisführung als eine bei den Vertretern .der bischöflịchen Suprematie allgemeine kennen lernen, und daß

1 H. Weinel in den Apokryphen d. NT., 1904, S. 224. A. Harnack Real-Enzykl.3 20, S. $526 \mathrm{f}$.

2 Auch in diesem Kapitel polemisiert Origenes scharf gegen gewinnsüchtige, tyrannische, ungebildete und unbedachte Bischöfe und Kleriker, denen die Gemeinden zu ihrem Schaden ausgeliefert seien. Das Einfangen Wohlhabender muß damals schon fast zum Sport geworden sein. Zu welchen Zuständen diese Jagd auf den Geldbeutel fúhrte, zeigen die Predigten des Chrysostomus und die Briefe des Hieronymus. 
von irgendeiner Exemplifizierung auf die römischen Verhältnisse keine Rede ist. Damit wird auch der bekannten Stelle bei Tertullian ein allgemeiner Sinn zugeschoben: Si quia dixerit Pelro dominus: super hanc petram atc. . . idcirco praesumis et ad te derivasse solvendi et adligandi potestaten, id cst ad ontnem ecclesian Pctri propinquam? $[21,9]$. Die Worte id est ad onnem ecclesiam Petri propinquam sind demnach nicht spezicll von der römischen Gemeinde zu verstchen, sondern heißen nur: "auf die ganze, Petrus nahestehende Kirche" d. h. auf die Kirche überhaupt, die auf den Felsen Petrus gebaut ist. Wieweit Tertullian hiermit ein von Kallist selbst geltend gemachtes Argument trifft, ist durchaus fraglich. In der literarischen Vertretung der bischöflichen Ansprüche kann der Grund auch sehr wohl von anderer Seite angeführt worden sein.

Der Trumpf, den Tertullian den Verfechtern der Amtskirche gegenüber mit Berufung auf die Geistesgemeinde ausspielte, konnte ihm nun dadurch aus der Hand genommen werden, daß sich auch die Märtyrer für eine mildere Behandlung der Unzuchtsünden ausgesprochen hatten, wie sie sich später den lapsi gegenüber ebenfalls dafür aussprachen. Galten die Mäityrer kraft ihres Martyriums als Geistesträger in spezifischem Sinn, ${ }^{1}$ so war ja die von Tertullian verlangte Bedingung gegeben: ecclesia quidem delicta donabit, sed ecclesia spiritus per spiritalenn hominem [22, 17]. Er leugnet nicht, daß Christus in dem Märtyrer ist $[22,6]$, aber er spricht dem Märtyrer die Befugnis ab, solche Sünden zu vergeben, deren Vergebung allein Gott zustehe; sufficiat martyri propria delicta purgasse $[22,4]$ fremde Sünden hat nur Gottes Sohn am Kreuz gebüßt. Die gewundene Dialektik, mit der Tertullian dieser seinem eigenen Standpunkt tötlichen Stellung der Märtyrer in der Bußfrage zu entgehen sucht, zeigt, daß er die Schwere des Argumentes empfand und macht es verständlich, daß er auf die kirchlichen Märtyrer so schlecht $z \mathrm{u}$ sprechen ist. $\mathrm{Daß}$ er mit seiner bissigen Bemerkung über solche Leute, die in die Bergwerke flüchten und von da als Märtyrer nach Hause zurückkehren, wo sie wegen neuer Sünden ein neues Martyrium auf sich nehmen müßten, einen Pfeil auf Kallist abschießt, ist bereits oben [S. 140] bemerkt worden. Vielleicht zielten auf diesen auch die weiteren Worte, daß der kein rechter Märtyrer sein könne, der um Pfennige bettle und in Wucherhände geraten sei. ${ }^{2}$

1 Vgl. m. Dissertation: „Tertullians Schriften de paen. u. de pud. “ 1890, S. 25 f. K. Müller, Kirchengesch. I, 1892, S. 115. A. Harnack, DG I 4 , 1909, S. $441^{1}$.

2 Quis marlyr, saeculi incola, medico obnoxius et feneralori $[22,3]$. Was der Arzt in diesem Zusammenhange soll, ist nicht recht verständlich. Vielleicht liegt ein Text- 
Aller Sarkasmus verdeckt jedoch die Schwächen der Beweisführung Tertullians an diesem Punkte nicht, läßt sie vielmehr erst recht deutlich hervortreten. In der Stellung Kallists wird übrigens die Haltung der Märtyrer nur als sekundäres Motiv mitgewirkt haben. Er bedarf ihrer Zustimmung von seinem Standpunkt aus nicht, da ihm die Amtsgewalt allein genügt.

Da man auf die Abweichungen des Berichtes bei Hippolyt gegenüber dem, was sich aus de pud.1 entnehmen läßt, zum Beweise dafür hingewiesen hat, ${ }^{1}$ daß Zephyrin gemeint sei, gilt es, diesen Bericht kurz zu mustern. Hippolyt behauptet [IX, 12, p. 758,99ff.], daß Kallist; um die Zahl seiner Anhänger zu vermehren, als erster auf die menschliche Begierde speku-

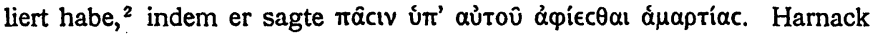
hat mit Recht darauf hingewiesen, ${ }^{3}$ daß das $\pi \hat{a} a v$ cum grano salis $\mathrm{zu}$ verstehen sei und nach de pud. 1 limitiert iverden müsse. Dafür spricht auch der Zusammenhang im folgenden. Kallist soll, nach der Behauptung Hippolyts [p. 460, 32 ff.] unverheirateten Frauen gestattet haben, in wilder Ehe, sei's mit Freien, sei's mit Sklaven zu leben, wodurch dann jene Frauen veranlaßt worden seien, $\mathrm{zu}$ unnatürlichen Mitteln zu greifen, um die Folgen dieser Verbindungen unsichtbar zu machen. Die Erörterung schließt mit den Worten [p. 460,36f.]: ópâtє

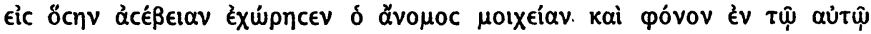
ठıঠáckwv. Es ist also ausdrücklich nur von Milde gegenüber den Hurern und Ehebrechern die Rede gewesen. Für den, der die sittlichen Zustände Roms in der Kaiserzeit kennt, für die häufig der Kaiserhof selbst das übelste Beispiel gab, ist das Vorgehen Kallists verständlich. Die Kirche war in der Tat an einem entscheidenden Wendepunkt angekommen. Wenn sie eine Idealgemeinde der Vollkommenen darstellen wollte, so mußte sie den Wald fauler Bäume rücksichtslos umhauen. Damit verzichtete sie aber auf jede Möglichkeit, in der Welt eine Rolle zu spielen. Sie verzichtete auch auf den wirkungsvollen Schutz, den unter Umständen die Mächtigen dieser Erde, wie Marcia, des Kaisers Konkubine, ihr hatten angedeihen lassen. Sie verzichtete weiter auf die reichen Mittel, jene großartige Wohltätigkeit zu üben,

fehler vor, etwa für maledico obnoxius feneratori , in der Schuld eines schmähenden (d. $h$. jüdischen) Wucherers ${ }^{\alpha}$.

1 A. Hauck, Real.-Enzykl. ${ }^{3}$ III, 641 .

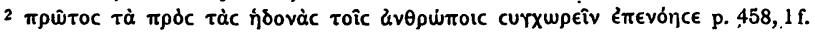

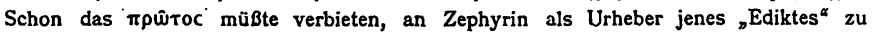
denken.

3 Dogmengeschichte $I^{4}, S .442^{3}$. 
die auch bei den Heiden Bewunderung erregte. Kallist hat zielbewulist diesen Schritt gewagt und die Tore der Kirche weiter aufgemacht. Was unter seinen Vorgängern stillschweigend geduldet worden war, hat er zum ausgesprochenen Prinzip gemacht. Er mußte bei diesem Vorgehen auf den Widerstand eines großen Teiles der Gemeinde gefaßt sein. Verächtlich spricht Hippolyt [p. 458, 1; 460, 24] von der

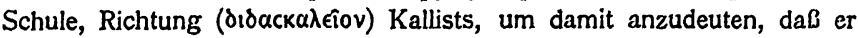

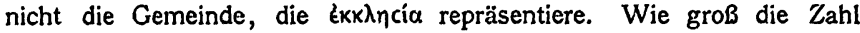
derer war, die an den urchristlichen Idealen festhielten, wissen wir nicht; aber sie kann nicht gering gewesen sein, wenn sie zu einer besonderen Gemeindebildung mit eigenem Bischof schritt.

Um die Gemeinde, die in der Bußpraxis seither die entscheidende Stimme gehabt hatte, auszuschalten, brachte Kallist einen neuen Amtsbegriff zur Geltung, der sich in den dogmatischen Streitigkeiten angebahnt und in den montanistischen Kämpfen befestigt hatte. Aus den brüderlichen Besprechungen, die in den Fragen des Glaubens und der Sitte von den Bischöfen abgehalten worden waren, hatten sich diese als die Wortführer der Gemeinden gezeigt, wie das der Entwicklung der Dinge in Kleinasien entsprach. Nhin griff die neue Auffassung vom Wesen und den Rechten des bischöflichen Amtes nach Westen hinüber. Die Gemeinde hat nun nichts mehr zu entscheiden: über die Aufnahme des Sünders bestimmt der Bischof. Mit dieser Auffassung vom Wesen der Amtsgewalt mag es denn auch zusammenhängen, da $B$ sich Kallist für die Unabsetzbarkeit der Bischöfe aussprach, selbst für den Fall, daß sie in eine Todsünde verfielen [p. 458, 10f.].

Die Anschauung, daß die Gemeinde nur die Vollkommenen in sich schließen dürfe, bekämpfte Kallist mit dem Hinweis auf das Gleichnis von dem Unkraut unter dem Weizen, auf die Arche Noah, in der reine und unreine Tiere zusammen waren, und auf das Wort des Paulus [Rö 14,4], daß niemand das Recht habe, über einen fremden Knecht zu urteilen. Damit gab er wertvolle Gedanken der Vergangenheit Preis. Aber immerhin ist $\mathrm{zu}$ bedenken, daß er nur einen Zustand sanktionierte, der doch tatsächlich bestand, über den schon der Prophet Hermas bittere Klage führte, und der sich auf die Dauer auch nicht ableugnen ließ. Aus dem Senfkorn war eben ein Baum geworden und es konnte nicht ausbleiben, daß sich an diesem Baum auch mancherlei dürre Äste fanden, die abzuhauen bedenklich sein mochte. So verzichtete Kallist lieber auf den Ruhm, über das Wenige getreu zu sein, sondern streckte die Hand nach dem neuen Land aus, das vor ihm lag. 